\title{
Effect of health education on breastfeeding initiation techniques among postnatal mothers admitted in a tertiary care centre of Raipur city, Chhattisgarh
}

\author{
Shubhra Agrawal Gupta ${ }^{1}$, Mini Sharma ${ }^{1}$, Abha Ekka ${ }^{2}$, Nirmal Verma ${ }^{1}$
}

\begin{abstract}
Department of Community Medicine, ${ }^{1} \mathrm{Pt}$ JNM Medical College, Raipur, ${ }^{2}$ Govt. Medical College, Ambikapur, Chhattisgarh, India
\end{abstract}

Received: 30 June 2018

Accepted: 01 August 2018

\section{*Correspondence:}

Dr. Mini Sharma,

E-mail: mrs.minisharma@gmail.com

Copyright: (c) the author(s), publisher and licensee Medip Academy. This is an open-access article distributed under the terms of the Creative Commons Attribution Non-Commercial License, which permits unrestricted non-commercial use, distribution, and reproduction in any medium, provided the original work is properly cited.

\begin{abstract}
Background: The health benefits of breastfeeding are well documented in public health and medical literature worldwide. It is reported in various studies that early lactation supported by correction of positioning and attachment of breastfeeding improves the rate of effective suckling. However, related to breastfeeding technique, no studies were conducted in Chhattisgarh, Therefore, this study was undertaken to assess the improvement in breastfeeding technique (positioning \& attachment) after intervention(health education and support) among mother-early neonate units admitted in postnatal ward immediately after delivery in a tertiary level health institute.

Methods: A Quasi-experimental (Single group pre and post design) carried out in hospital settings from August to September 2014. This study involved 414 both preterm and term babies who were born during the study period at Dr. BRAM hospital, Raipur with their mothers.Mothers were observed for breast feeding technique on first day followed by correction and post interventional observation.

Results: After intervention statistically significant improvement was seen in overall body positioning status and attachment during breast feeding $43.3 \%, 42.1 \%$ respectively.

Conclusions: Present study indicate that educating and supporting the mothers regarding correct breastfeeding technique is important to help them in the stage when they are establishing breastfeeding. This also avoids early and late problems related to breastfeeding.
\end{abstract}

Keywords: Breast feeding, Positioning and attachment, Post-intervention, Postnatal mothers

\section{INTRODUCTION}

Breastfeeding is essential for the health and development of children. It is also important for the health of the mothers. ${ }^{1}$ Breast milk is a perfectly balanced source of nutrition and contains a variety of nutrients and immunological factors that cannot be replicated. ${ }^{2}$

Exclusive breastfeeding up to first 6 month of life and after 6 months breastfeeding along with complementary food till 2 years of age and beyond provides various health benefits to both mother and child. It also protects the child from various acute and chronic diseases. Breast fed infants are 6 to 10 times less likely to die than infants who are breastfed. ${ }^{3}$

While, being a natural act, breastfeeding is a learned behaviour. ${ }^{4}$ The key to successful breastfeeding is likely to be information, education and communication (IEC) strategies aimed at promoting proper breastfeeding technique. $^{5}$ For promoting and supporting the breastfeeding, breastfeeding promotion network of India was started in 1991. In 2005 integrated management of neonatal and childhood illness (IMNCI) was started 
under national health mission. ${ }^{3}$ The IMNCI strategy recommended a systematic assessment of breastfeeding and emphasized in the counselling of the mother on the proper positioning and the attachment of the infant to the breast to facilitate effective suckling. An effective sucking technique is considered important to establish breastfeeding, to ensure milk transfer, and to prevent breastfeeding problems. Good positioning and attachment of the baby during breastfeeding may result in effective sucking which facilitates milk production and milk release. ${ }^{6}$

The effective breastfeeding is depend upon correct positioning of mother and baby and attachment of baby to mother's breast. ${ }^{4}$ Correct positioning and attachment of the baby during breastfeeding may result in effective suckling which intern facilitates milk production and release thereby increasing the duration of breastfeeding. ${ }^{7}$ 10 Similarly, incorrect breast feeding technique may results in lactation failure, musculoskeletal pain, generalized myalgia, breast pain, cracked nipples and nipple trauma. ${ }^{11,12}$

After the delivery, there is an opportunity to demonstrate, educate and support the mothers about the correct positioning and the attachment of the baby to the breast. It is observed that most of the breastfeeding difficulties can be avoided if good attachment and positioning. This can be achieved at the first and early feed., , $^{3-15}$

It was found that the number of published studies addressing the proper positioning and attachment of the babies of breastfeeding is relatively scarce in Chhattisgarh. Hence, the present study was undertaken with the objective to assess the improvement in breastfeeding technique (positioning and attachment) after intervention among mothers-early neonates units admitted in postnatal ward immediately after delivery in a tertiary level health care institute.

\section{METHODS}

A quasi-experimental (Single group pre and post design) was carried out in post natal ward of obstetrics and gynaecology department of Dr. BRAM hospital, Raipur, Chhattisgarh, India from August to September 2014.

This study comprised of all the 414 babies both preterm and term who were born during the study period (immediate postnatal period) at Dr. BRAM hospital, Raipur with their mothers as mother-early neonate units. Those having any congenital problem or medical problem were excluded. Mothers were informed about the purpose and intervention done for the study and informed verbal consent was taken before data collection.

For assessment of breastfeeding positioning and attachment pre and post intervention (health education, demonstration and support) was done among study subjects.
Institutional ethic committee approval was taken before stating the data collection. The concerned authorities were explained about the nature of study and permission was taken.

The information on the Maternal and neonatal characteristics like age, education, economic status, parity, birth weight of their babies, breast problem, preterm/full term etc was obtained by using pre-designed, pre-tested Semi structured questionnaire.

For assessment of breastfeeding positioning and attachment, observation was done by trained and qualified persons in IMNCI guidelines while mother feeding their baby on first day for 4 minutes and then they recorded the babies positioning and attachment to the breast according to IMNCI guidelines.Later, irrespective of the correct or incorrect positioning or attachment of breast feeding technique, intervention (Health education, demonstration and Support) of correct technique among all the mothers was done and on next day second assessment of correct positioning and attachment of breastfeeding was done.

Positioning at the breast has been defined as the relationship between the baby's body and the mother's, whereas attachment is the relationship between the baby's mouth and the mother's breast. ${ }^{16}$

The following criteria of positioning (mother and early neonates), attachment and effective suckling during breastfeeding based on IMNCI criteria were adopted.

\section{Breastfeeding body positioning criteria}

i) Baby neck and body straight, ii) baby close to mother, iii) baby turn toward mother, iv) baby whole body supported by mother.

Correct body positioning means when all four criteria of body positioning was fulfilled.

\section{Breastfeeding baby's attachment criteria}

i) Chin touching breast, ii) mouth wide and open, iii) lower lip turned out, iv) upper areola more visible.

Correct baby's attachment means when all four criteria of baby's attachment was fulfilled

\section{Effective suckling criteria}

Baby takes slow, deep sucks, sometimes pausing.

Correct effective suckling means when all three criteria of effective suckling was fulfilled.

\section{Statistical analysis}

The data were analyzed in excel. To test the associations between maternal and neonatal characteristic and 
breastfeeding technique chi-square test was applied. A result with a $\mathrm{p}$ value of less than 0.05 was considered as statistically significant.

\section{RESULTS}

Of the 414 study subjects, majority of the mothers were between 20 to 30 years of age $(93 \%)$, followed by below 20 years $(3.9 \%)$ and more than 30 years $(3.1 \%)$. Among all early neonates, $46.6 \%$ were male and remaining $53.4 \%$ were female. $96.2 \%$ were Hindus. Majority of them $31.4 \%$ were educated up to middle school and $18.3 \%$ were illiterate and living with joint family (65.7\%). 93.1\% mothers were housewives. $55.1 \%$ mothers were primigravida, most of the early neonates were full term $(96.9 \%)$ and only $(3.2 \%)$ were preterm. (76.6\%) early neonates had normal birth weight (more than $2.5 \mathrm{~kg}$ ) and $23.4 \%$ had low birth weight (more than $2.5 \mathrm{~kg}$ ). Normal/assisted vaginal delivery (64.3\%) and Caesarean section $(35.7 \%) .85 .3 \%$ babies had not taken prelacteal fed and Colostrums were fed to $83.6 \%$ of the babies. Babies with low birth weight were $23.4 \%$ (Table 1).

Improvement after post-intervention health education related to the positioning and attachment of the babies during breastfeeding showed statistical significance $28.2 \%$ and $28.3 \%$ improvement were seen in mothers who kept their baby's neck and body straight with baby's body close to them respectively. $9.4 \%$ improvement was seen in which baby's body was turned towards their mother and $12.8 \%$ baby's whole body was kept supported with both the hands. It was noted that in relation to overall (all 4 correct) body positioning status statistically significant $(\mathrm{p}<0.001) 43.3 \%$ improvement was seen.

Table 1: Socio-demographic profile of study subjects $(n=414)$.

\begin{tabular}{|c|c|c|c|}
\hline Variables & & & Frequency (\%) \\
\hline \multirow{19}{*}{ Related to mother } & \multirow{3}{*}{ Age in years } & $<20$ & $16(3.9)$ \\
\hline & & $20-30$ & $385(93)$ \\
\hline & & $>30$ & $13(3.1)$ \\
\hline & \multirow{5}{*}{ Education } & Illiterate & 77 (18.3) \\
\hline & & Primary school & $104(25.1)$ \\
\hline & & Middle school & $130(31.4)$ \\
\hline & & High school & $87(21)$ \\
\hline & & Graduate \& PG & $14(3.4)$ \\
\hline & \multirow{2}{*}{ Working status } & Housewife & $385(93.1)$ \\
\hline & & Working & $29(6.9)$ \\
\hline & \multirow{2}{*}{ Religion } & Hindu & $398(96.2)$ \\
\hline & & Muslim & $16(3.8)$ \\
\hline & \multirow{3}{*}{ Caste } & General & $84(20.3)$ \\
\hline & & SC \& ST & $135(32.6)$ \\
\hline & & OBC & $195(47.1)$ \\
\hline & \multirow{2}{*}{ Types of family } & Nuclear & $142(34.3)$ \\
\hline & & Joint & $272(65.7)$ \\
\hline & \multirow{2}{*}{ Parity } & Primipara & $228(55.1)$ \\
\hline & & Multipara & $186(44.9)$ \\
\hline \multirow{15}{*}{ Related to baby } & \multirow{2}{*}{ Time of delivery } & Term & $401(96.9)$ \\
\hline & & Preterm & $13(3.2)$ \\
\hline & \multirow{2}{*}{ Mode of delivery } & $\begin{array}{l}\text { Normal/assisted vaginal } \\
\text { delivery }\end{array}$ & $266(64.3)$ \\
\hline & & Caesarean section & $148(35.7)$ \\
\hline & \multirow{2}{*}{ Sex of baby } & Male & $193(46.6)$ \\
\hline & & Female & $221(53.4)$ \\
\hline & \multirow{2}{*}{ Birth weight } & Low birth weight & $97(23.4)$ \\
\hline & & Normal weight & $317(76.6)$ \\
\hline & \multirow{3}{*}{ Birth order } & 1 & $228(55.1)$ \\
\hline & & 2 & $147(35.5)$ \\
\hline & & 3 or more & $39(9.4)$ \\
\hline & \multirow{2}{*}{ Prelacteal feed } & Yes & $61(14.7)$ \\
\hline & & No & $353(85.3)$ \\
\hline & \multirow{2}{*}{ Colostrum } & Fed & $346(83.6)$ \\
\hline & & Not fed & $68(16.4)$ \\
\hline
\end{tabular}


Table 2: Assessment of improvement pertaining to breast positioning and attachment before and after health intervention by observation $(n=414)$.

\begin{tabular}{|lllll|}
\hline Observations & $\begin{array}{l}\text { Pre-intervention } \\
\left(\begin{array}{l}\text { st visit) } \\
\text { No }(\%)\end{array}\right.\end{array}$ & $\begin{array}{l}\text { Post-intervention } \\
\text { (Follow up) } \\
\text { No }(\%)\end{array}$ & $\begin{array}{l}\text { Improvement } \\
(\%)\end{array}$ & P value \\
\hline Body position & $199(48.1)$ & $316(76.3)$ & 28.2 & $<0.001$ \\
\hline Baby's neck and body straight & $150(36.2)$ & $267(64.5)$ & 28.3 & $<0.001$ \\
\hline Baby's body close to mother & $194(46.9)$ & $233(56.3)$ & 9.4 & $<0.001$ \\
\hline Baby's body turn towards mother & $87(21)$ & $140(33.8)$ & 12.8 & $<0.001$ \\
\hline Baby's whole body supported by mother & $82(19.8)$ & $261(63.1)$ & 43.3 & $<0.001$ \\
\hline Overall correct positioning status & & & 30 & $<0.001$ \\
\hline Attachment & $248(59.9)$ & $372(89.9)$ & 13.8 & $<0.001$ \\
\hline Chin of the baby touching the breast & $311(75.1)$ & $368(88.9)$ & 26.1 & $<0.001$ \\
\hline Baby's mouth is widely open & $82(19.8)$ & $190(45.8)$ & 21.7 & $<0.001$ \\
\hline Lower lip turned out & $125(30.2)$ & $215(51.9)$ & 42 & $<0.001$ \\
\hline Upper areola more visible & $78(18.8)$ & $252(60.9)$ & & \\
\hline Overall correct attachment status & & & & \\
\hline
\end{tabular}

Table 3: Assessment of effective suckling with post-interventional positioning and attachment (n=414).

\begin{tabular}{|llll|}
\hline Post-intervention & $\begin{array}{l}\text { Suckling } \\
\text { Effective } \\
\mathbf{n}(\boldsymbol{\%})\end{array}$ & $\begin{array}{l}\text { Ineffective } \\
\mathbf{n}(\boldsymbol{\%})\end{array}$ & P value \\
\hline Positioning $(\mathbf{n = 2 6 1 )}$ & $230(88.1)$ & $31(11.9)$ & $<0.0001$ \\
\hline Attachment $(\mathbf{n = 2 5 2})$ & $234(92.9)$ & $18(7.1)$ & $<0.0001$ \\
\hline
\end{tabular}

Related to improvement in attachment revealed that $30 \%$ statistically significant improvement $(\mathrm{p}<0.001)$ was seen in which babies chin was touching the mother's breast. In $13.8 \%$ babies, the mouth was widely open and in $26.1 \%$ the lower lip was turned outwards and upper areola was more visible in $21.7 \%$ study subjects. Similarly, with respect to overall (all 4 correct) attachment $42.1 \%$ improvement was observed (Table 2).

After correction of positioning and attachment statistically significant association (p.0001) with effective suckling was seen in $88.1 \%$ and $92.9 \%$ study subjects respectively (Table 3).

\section{DISCUSSION}

This study was done to observe the post-intervention breastfeeding correction among mother-early neonates units in a tertiary-care hospital.

Apart from knowing the factors responsible for incorrect technique of breast-feeding among mother-early neonates units, this study also gives an opportunity to educate and support the mothers about the correct positioning and the attachment of breast-feeding technique. For getting all the benefits of breastfeeding effective breastfeeding is must.

In the present study only $14.7 \%$ babies had taken prelacteal fed. On the contrary study, done by Parashar in Delhi showed $84 \%$ prevalence of prelacteal fed. ${ }^{3}$ The reason could be because the delivery were in hospital settings in our study. In the current study, $16.4 \%$ of all newborn were not given colostrums. Similarly study done by Katara et al showed that colostrum was discarded by $13 \%$ of mothers. ${ }^{17}$

In our study, $19.8 \%, 18.8 \%$ of mother- early neonates units had all 4 correct positioning and attachment before intervention and after intervention $63.1 \%$ and $60.9 \%$ of mother- early neonates units had all 4 correct positioning and attachment, respectively.

Similarly, improvement in their correct body positioning and attachment were seen at $43.3 \%$ and $42.1 \%$, respectively.

Shrivastava et al, explained similar results showing that $47.4 \%$ babies were correctly positioned and $41.2 \%$ babies were well attached, which is almost similar to our study. ${ }^{4}$ This could be due to that the study setting was same. Another study done by Mannan et al, found that $74 \%$ infants were in correct breastfeeding position while good attachment was found in $72.3 \%$ infants, which is a bit higher than our study. ${ }^{18}$ Whereas, Essa et al, found that $26.3 \%$ and $36 \%$ of respondent had good body position and good attachment grade respectively. ${ }^{19}$

In our study, significant association between effective suckling and correct positioned and attachment were occur, after intervention. Similar finding occur in a study done in North India in which after post intervention deep 
and well suckling was observed. ${ }^{20}$ In our study we analyze the improvement after post intervention contrast to other study in which this was lacking. ${ }^{21}$

\section{CONCLUSION}

Thus present study concluded that observation and correction of breastfeeding technique is important to help mothers in the stage when they are establishing breastfeeding to avoid early and later problems. Thus this study endorse that each mother especially, in the post natal period before discharge from the hospital after delivery should be observed for correct positioning and correct attachment,at the onset of breastfeeding and if there is a need teach mothers about the correct technique of breastfeeding.

\section{ACKNOWLEDGEMENTS}

We are very thankful to all the mothers-early neonates units who participated in the study without them this study would not have been conducted.

\section{Funding: No funding sources}

Conflict of interest: None declared

Ethical approval: The study was approved by the Institutional Ethics Committee

\section{REFERENCES}

1. Guide TS. Breastfeeding Counselling a Training Course, 1993.

2. Gartner LM, Morton J, Lawrence RA, Naylor AJ, O'Hare D, Schanler RJ, Eidelman AI. Breastfeeding and the use of human milk. Pediatrics. 2005;115(2):496-506.

3. Parashar M, Singh S, Kishore J, Patavegar BN. Breastfeeding Attachment and Positioning Technique, Practices, and Knowledge of Related Issues Among Mothers in a Resettlement Colony of Delhi. ICAN. 2015;7(6):317-22.

4. Shrivastava P, Saha I, Nandy S. A study on feeding practice of under 6 months infants attending the nutrition clinic of a tertiary care hospital of West Bengal, India. Epidemiol, Biostatistics Public Health. 2013;10(2):1-6.

5. Dhandapany G, Bethou A, Arunagirinathan A, Ananthakrishnan S. Antenatal counseling on breastfeeding-is it adequate? A descriptive study from Pondicherry, India. Int Breastfeeding $\mathbf{J}$. 2008;3(1):5.

6. Johnson R, Taylor W. Skills for Midwifery Practice.

7. Righard L, Alade MO. Sucking technique and its effect on success of breastfeeding. Birth. 1992;19(4):185-9.

8. Ingle GK, Malhotra C. Integrated management of neonatal and childhood illness: an overview. Indian J Community Med. 2007;32(2):108.
9. Ingram J, Johnson D, Greenwood R. Breastfeeding in Bristol: teaching good positioning, and support from fathers and families. Midwifery. 2002;18(2):87-101.

10. Henderson A, Stamp G, Pincombe J. Postpartum positioning and attachment education for increasing breastfeeding: a randomized trial. Birth. 2001;28(4):236-42.

11. Tella K, Guruvare S, Hebbar S, Adiga P, Rai L. Knowledge, attitude, and practice of techniques of breast-feeding among postnatal mothers in a coastal district of Karnataka. Int J Med Sci Public Heal. 2016;5(1):28.

12. Tait P. Nipple pain in breastfeeding women: causes, treatment, and prevention strategies. Journal of Midwifery \& Women's Health. 2000;45(3):212-5.

13. Righard L. Are breastfeeding problems related to incorrect breastfeeding technique and the use of pacifiers and bottles? Birth. 1998;25(1):40-4.

14. Coca KP, Gamba MA, Sousa e Silva RD, Abrão AC. Does breast feeding position influence the onset of nipple trauma? Revista da Escola de Enfermagem da USP. 2009;43(2):446-52.

15. Shimoda GT, Silva IA, Santos JL. Characteristics, frequency and factors present in nipples damage occurence in lactating women. Rev Bras Enferm. 2005;58:529-34.

16. Colson S. Maternal breastfeeding positions: Have we got it right? The practising midwife. 2005;8(11):29-32.

17. Katara PS, Patel SV, Mazumdar VS, Mehta KG, Shringarpure K, Bakshi HN. A study on feeding practices among infants aged upto 6 months in urban slums of Vadodara. Indian J Maternal Child Health. 2011;13(2):6.

18. Mannan I, Rahman SM, Sania A, Seraji HR, Arifeen SE, Winch PJ, Darmstadt GL, Baqui A. Can early postpartum home visits by trained community health workers improve breastfeeding of newborns? J Perinatol. 2008;28(9):632.

19. Essa RM, Ebrahim EM. Effect of breast milk versus therapeutic honey (Apicare) on cracked nipples' healing. Life Sci J. 2013;10(1):2137-47.

20. Gupta M, Aggarwal AK. Feasibility study of IMNCI guidelines on effective breastfeeding in a rural area of North India. Indian J Community Med. 2008;33(3):201-3.

21. Thakre SB, Thakre SS, Ughade SM, Golawar S, Thakre AD, Kale P. The Breastfeeding Practices: The Positioning and Attachment Initiative Among the Mothers of Rural Nagpur. J Clin Diagnos Res. 2012;6(7):1215-8.

Cite this article as: Gupta SA, Sharma M, Ekka A, Verma N. Effect of health education on breastfeeding initiation techniques among postnatal mothers admitted in a tertiary care centre of Raipur city, Chhattisgarh. Int J Community Med Public Health 2018;5:4340-4. 